\title{
Natural Convection in Tilted Rectangular Cavity subjected to $\mathbf{T}_{A}$
}

\author{
Djamila Benyoucef ${ }^{1}$, Mostefa Zeroual $^{1}$ and Hocine Ben Moussa ${ }^{2}$ \\ ${ }^{1}$ Department of Physics, Faculty of Sciences, University of Batna, Algeria \\ ${ }^{2}$ Department of Mechanical Engineering, Faculty of Engineering, University of Batna, Algeria \\ \{djamila.phy\}@gmail.com
}

Keywords: CFD Simulation, Inclined cavity, Natural Convection, Spectral Analysis.

\begin{abstract}
The present study investigates the spectral analysis for natural convection in a tilted rectangular cavity, lled with high Prandtl oil "Pr $=880$ " by the code CFD. A constant vertical temperature gradient has been performed by subjecting the horizontal walls to constant temperatures $T_{h}$ and $T_{c}$; respectively. Other walls are adiabatic except the left small sidewall is differentially heating with temperature $T_{A}$ creating the horizontal temperature gradient. The results are presented for different values of lateral heating and inclination angle. The spectral analysis is used to identify and show effects on the original oscillation of the natural convection by the various investigated parameters $\left(T_{A}\right.$ and $\left.\theta\right)$.
\end{abstract}

\section{INTRODUCTION}

In the engineering field, closed enclosures heated from below (Rayleigh-Bnard convection) and differentially heated are a particular interest. The cooling Case of electronic or electrical circuits in closed boxes are excellent examples (Bejan, 1984) and (Ostrach, 1988). The horizontal and inclined enclosures cases of natural convection has been extensively studied numerically (de Vahl Davis and Jones, 1983), (Khalifa, 2001) and (Khezzar et al., 2012). For several years, a considerable numerical work has been carried out considering more complex thermal and geometric boundary conditions, not only due to the many technological applications, but also because they constitute an ideal case for developing digital models to solve the equations of Navier-Stokes.

The spectral analysis is a mean to clarify the original amplitude of any system. It is presented the stability of the natural convection by a magnitude as a function to the frequency in different characteristic points (Mergui and Penot, 1996), (Douamna et al., 1999) and (Laouar et al., 2007). The purpose of this work is to predict the flow pattern of the natural convection in cavity under diverse thermal and geometric conditions. Dynamic and thermal maps are displayed. The visual form for convective stability is plotted by Fluent FFT. A finite volume analysis is performed by the Ansys / Fluent 17.0 code for a two-dimensional enclosure in an unstable state.

\section{PROBLEM FORMULATION}

We consider a rectangular cavity $\left(10 \times 1 \mathrm{~cm}^{2}\right)$ (Figure 1), Filled with silicon oil $\left(\operatorname{Pr}=880\right.$ at $\left.25^{\circ} \mathrm{C}\right)$. The bottom and the top walls are maintained at different temperature $\mathrm{T}_{h}$ and $\mathrm{T}_{c}$, respectively. The others are adiabatic except the left small sidewall is maintained at temperature $\mathrm{T}_{A}$ (variable).

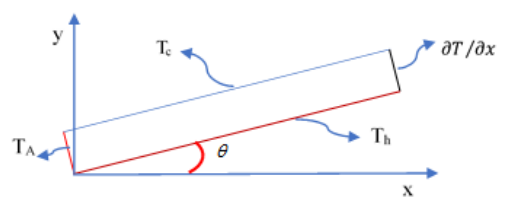

Figure 1: Treated problem.

The continuity, momentum and energy equations can be written for a 2D laminar flow in unsteady state regime. To write the governing equations, it's assumed that Boussinesq approximation is accepted (Gray and Giorgini, 1976).

$$
\begin{gathered}
\frac{\partial u}{\partial x}+\frac{\partial v}{\partial y}=0 \\
\frac{\partial u}{\partial t}+u \frac{\partial u}{\partial x}+v \frac{\partial u}{\partial y}=\frac{1}{\rho} \frac{\partial P}{\partial x}+\frac{\mu}{\rho}\left(\frac{\partial^{2} u}{\partial x^{2}}+\frac{\partial^{2} u}{\partial y^{2}}\right)+g \beta\left(T-T_{0}\right) \cos \theta \\
\frac{\partial v}{\partial t}+u \frac{\partial v}{\partial x}+v \frac{\partial v}{\partial y}=\frac{1}{\rho} \frac{\partial P}{\partial y}+\frac{\mu}{\rho}\left(\frac{\partial^{2} v}{\partial x^{2}}+\frac{\partial^{2} v}{\partial y^{2}}\right)+g \beta\left(T-T_{0}\right) \sin \theta \\
\frac{\partial T}{\partial t}+u \frac{\partial T}{\partial x}+v \frac{\partial T}{\partial y}=\frac{\lambda}{\rho C_{P}}\left(\frac{\partial^{2} T}{\partial x^{2}}+\frac{\partial^{2} T}{\partial y^{2}}\right)
\end{gathered}
$$




\subsection{Boundary conditions}

The boundary conditions (Zeroual and Cerisier, 2000) are :

$$
\begin{gathered}
\text { for all walls, } u=v=0 \\
\frac{\partial T}{\partial x}=0, \text { at } \mathrm{x}=\mathrm{L} ; \quad T_{A}=\text { variable, at } \mathrm{x}=0 \\
T_{h}=27,6 k, \text { at } \mathrm{y}=0 ; \quad T_{c}=19,4 k, \text { at } \mathrm{y}=\mathrm{H}
\end{gathered}
$$

The system of equations (1)-(4) with the boundary conditions stated above is solved by using finite volume described by Patankar (Patankar, 1980) method and the SIMPLE algorithm (Van Doormaal and Raithby, 1984)

\section{RESULT AND DISCUSSION}

\subsection{Thermal and dynamic fields}

A numerical study has been carried out to simulate convective problem in an inclined rectangular cavity with three heating wall at high Prandtl number. Considering different values of $\Delta T$ and $\theta$ in the natural convection modeling using Ansys / Fluent gives us the dynamic and thermal maps represented in Figures (2, 3, 4 and 5). For each figure; we present the velocity (on the low (a)) and isotherms (on the top (b)) to show the effects of different inclination for the four lateral heating cases $\left(T_{A}=0^{\circ} \mathrm{C}, 30,3^{\circ} \mathrm{C}, 52,7^{\circ} \mathrm{C}\right.$ and $67,6^{\circ} \mathrm{C}$ ). It is clear that the thermal and dynamic pattern of the convective flow is destabilized for each lateral heating value as a function to the tilted angle. We can note that in each time that the tilt angle increasing relative to the horizontal for the same lateral heating value:

- For $\theta=0^{\circ}$ : The velocity field is rolling in the whole domain. We observe ten transverse rolls parallel at the small side, where this rolls number decrease with the increase imposed temperature $T_{A}$. Similarly; The pattern Bnard structure changed by presence of the induced roll and The isotherms has lost their temporal oscillation near the lateral heating $T_{A}$.

- For for other angles $(\theta=10,25,60$ and 90 : )Atlowtemperature $\mathrm{T}_{A}$; the thermal and dynamic behavior deformed and located in different places of the cavity for the firsts angles, which gradually disappear from $\theta \geq 60$ until the vertical case $(\theta=90)$.

- The isotherms has lost gradually the temporal oscillation for the two parameters $\left(\theta\right.$ and $\left.T_{A}\right)$ and

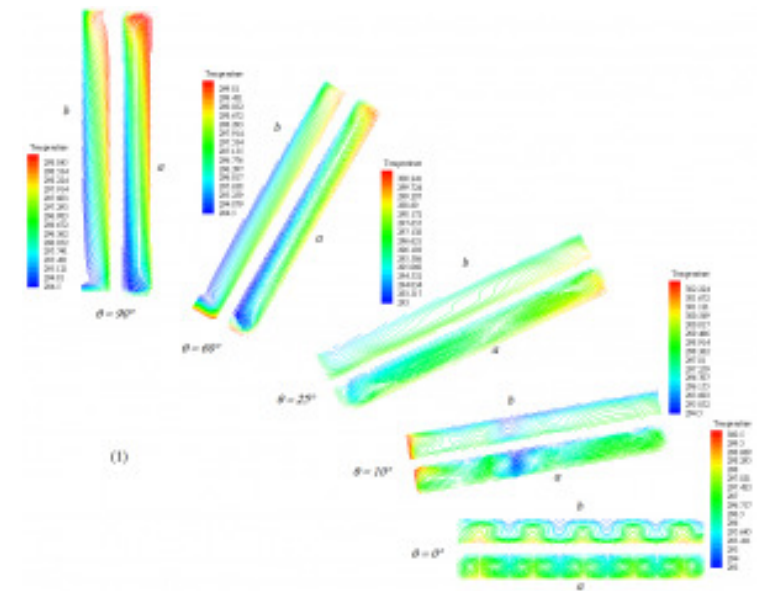

Figure 2: Velocity field (a) and isotherms (b) patterns obtained without lateral heating $T_{A}$.

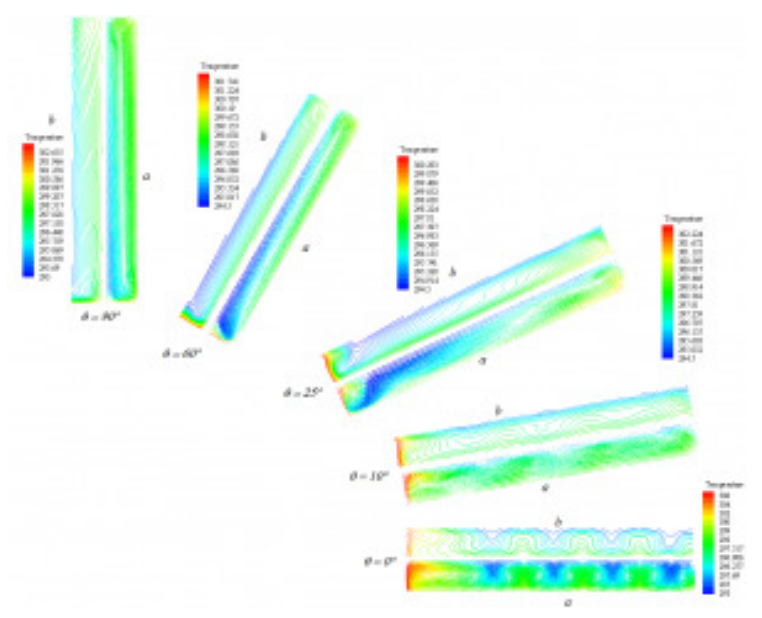

Figure 3: Velocity field (a) and isotherms (b) patterns obtained with lateral heating $T_{A}=30,3^{\circ} \mathrm{C}$.

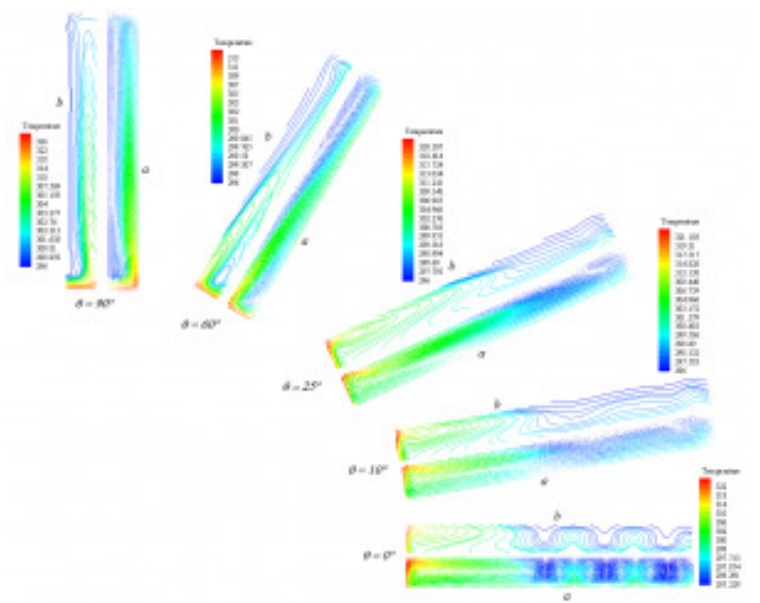

Figure 4: Velocity field (a) and isotherms (b) patterns obtained with lateral heating $T_{A}=52,7^{\circ} \mathrm{C}$. 
the two gradients temperature effect on the studied domain without being dominant. For the angle range $25^{\circ} \leqslant \leqslant 60^{\circ}$ : a secondary ascending flow in the opposite inclination direction created by the high lateral heating.

- The secondary flow created by the high lateral heating at the high inclination $\left(90^{\circ}\right)$ near the heating wall until it is included in the whole cavity.

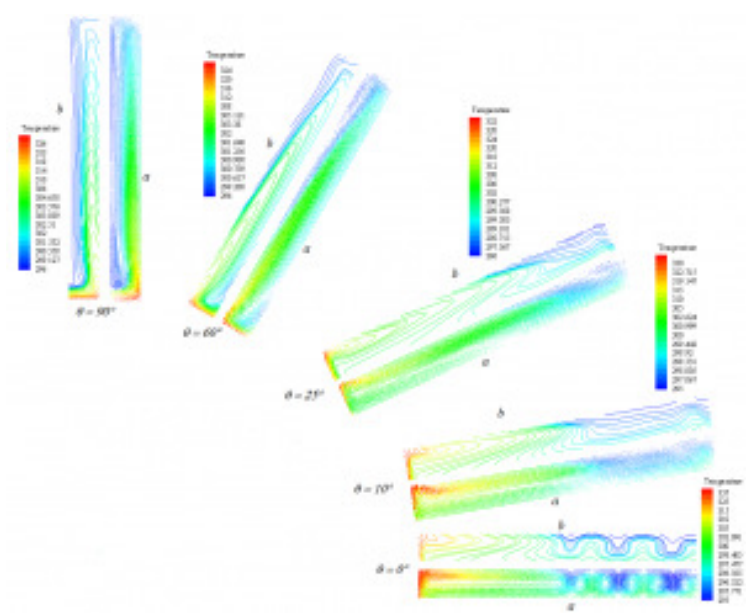

Figure 5: Velocity field (a) and isotherms (b) patterns obtained with lateral heating $T_{A}=67,6^{\circ} \mathrm{C}$.

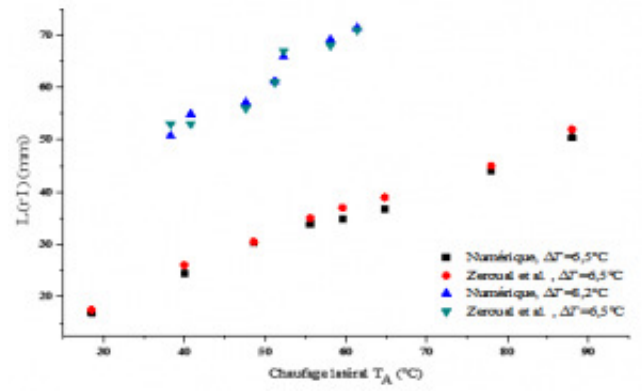

Figure 6: Waist variation of (rI) as a function of temperature $T_{A}$ for $\Delta T_{v}=8.2 \mathrm{~K} ; 6.5 \mathrm{k}$

The parameter $T_{A}$ effects on the pattern convective flow specially at the length of the induced roll. Diagram presented in Figure 6 compare numerical and experimental results for the influence of the lateral heating on the induced roll structure. The parameter $T_{A}$ effects on the pattern convective flow specially for $\theta=0^{\circ}$ at the length of the induced roll. Diagram presented in Figure 6 confirms the direct proportionality, it compares the effect of the variation of the induced roll length (rI) as a function to the lateral temperature $\left(T_{A}\right)$ for two differences vertical temperature $\left(\Delta T=6,5^{\circ} \mathrm{C}\right.$ and $\left.\Delta T=8,2^{\circ} \mathrm{C}\right)$. The comparison is made between the numerical results found and the experimental results (Zeroual and Cerisier, 2007).
The graphs are strictly the same, with some difference approximately $0,5 \%$ and $0,3 \%$ for $\Delta T=6,5 \mathrm{k}$, $\Delta T=8,2 \mathrm{k}$ respectively. The length of the (rI) is largely affected by the variation of vertical $\Delta T$; it increases when $\Delta T_{v}$ vertical decreases.

\subsection{Spectral analysis}

The spectral analysis method depends to chose various points in the cavity and to plot their amplitude in function to the frequency. The point chosen $\left(P_{1}=\right.$ $0.5 \mathrm{~cm})$ is located near the lateral heating along to $\mathrm{x}$ axis and in the center according to y-axis. Figures 7 , 8, 9 and 10 present the spectral analysis for the chosen point as a function to four lateral heating values and various tilted angle. We can be distinguished by figures:


Figure 7: Spectral analysis without lateral heating
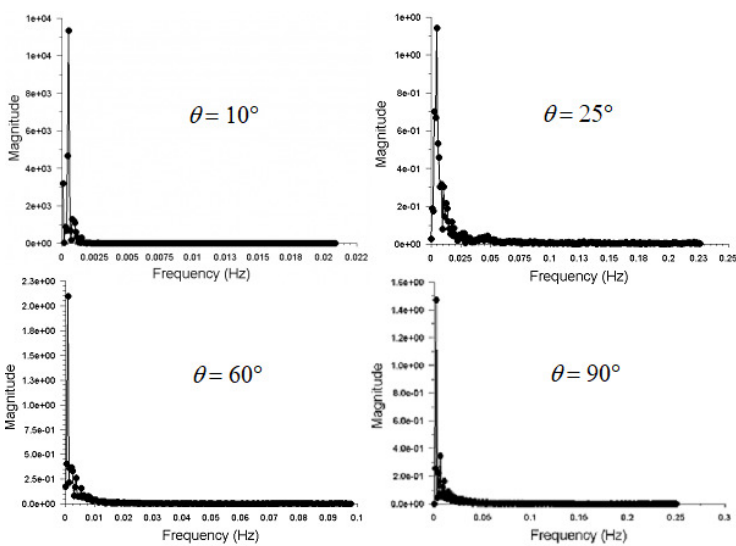

Figure 8: Spectral analysis for $T_{A}=30,3^{\circ} \mathrm{C}$.

- For $T_{A}=0{ }^{\circ} \mathrm{C}$ (Figure 7): Tilted angle destabilized the amplitude of the convective system; expressed by small vibrations near to the original amplitude. 
- The fluctuations have an importance for all values of $T_{A}$ and $\theta$, where their amplitude and their presence concentration vary either directly or inversely with the increase of the lateral heating for each angle (Benyoucef et al., 2017).

- For low temperatures; the concentration of the fluctuations is large at low amplitude to the original amplitude of the convective system (Figures 7 and 8). Although this concentration is crushed for high side heating in all angles but with high amplitudes (Figures 9 and 10).


Figure 9: Spectral analysis for $T_{A}=52,7^{\circ} \mathrm{C}$.
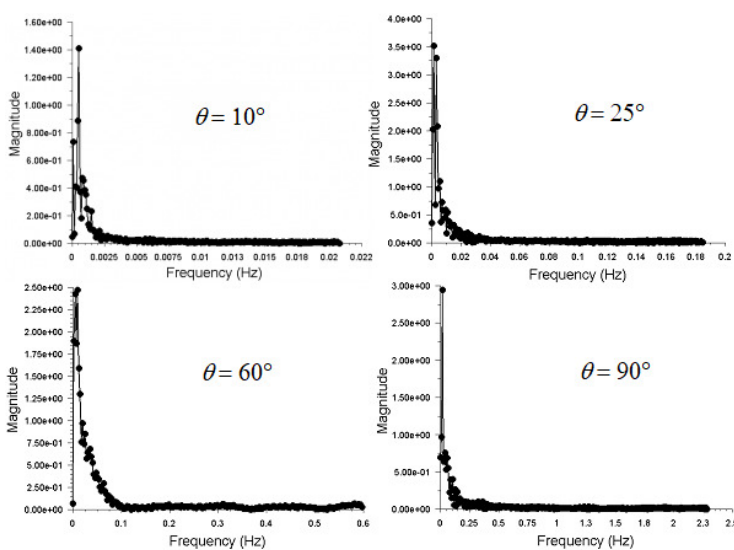

Figure 10: Spectral analysis for $T_{A}=67,6^{\circ} \mathrm{C}$.

\section{CONCLUSIONS}

Natural convection in rectangular tilted cavity was numerically simulated. The computations were performed by ANSYS / Fluent based on finite volume method. Attention is focused on the tharmal and dynamic maps also on the spectral analysis of the natural convection and how flow pattern is affected by the variation in both parametres $\mathrm{T}_{A}$ and $\theta$. It's found that increasing of beyond $0^{\circ} \mathrm{C}$ and $0^{\circ}$ respectively, destabilize the convective structure in the unsteady state for all $\mathrm{T}_{A}$ and $\theta$ tested values . as well indicated in the spectral analysis by a complex behavior in concentration and amplitude number was found.

\section{REFERENCES}

Bejan, A. (1984). Convection heat transfer. John Wiley \& Sons, New York.

Benyoucef, D., Zeroual, M., and Benmoussa, H. (2017). Natural convection in tilted rectangular cavities due to bidirectional temperature gradient. International Journal of Heat and Technology, 35(4):883-892.

de Vahl Davis, G. and Jones, I. (1983). Natural convection in a square cavity: a comparison exercise. International Journal for numerical methods in fluids, 3(3):227-248.

Douamna, S., Hasnaoui, M., and Abourida, B. (1999). Convection naturelle instationnaire dans une géométrie répétitive périodiquement chauffée par le bas: analyse par la transformation rapide de fourier. International journal of thermal sciences, 38(9):797-807.

Gray, D. and Giorgini, A. (1976). The validity of the boussinesq approximation for liquids and gases. volume 19, pages 545-551. International Journal of Heat and mass Transfer.

Khalifa, A.-J. N. (2001). Natural convective heat transfer coefficient-a review: I. isolated vertical and horizontal surfaces. Energy conversion and management, 42(4):491-504

Khezzar, L., Siginer, D., and Vinogradov, I. (2012). Natural convection of power law fluids in inclined cavities. International Journal of Thermal Sciences, 53:8-17.

Laouar, S., Abada, L., Mezaache, E.-H., and Daguenet, M. (2007). Convection naturelle instationnaire dans une enceinte bidimensionnelle carrée-bifurcation vers le chaos. page $5 \mathrm{p}$.

Mergui, S. and Penot, F. (1996). Convection naturelle en cavité carrée différentiellement chauffée: investigation expérimentale à ra $=1,69 \times 109$. International Journal of Heat and Mass Transfer, 39(3):563-574.

Ostrach, S. (1988). Natural convection in enclosures. volume 110, pages $1175-1190$. The publishing company.

Patankar, S. (1980). Numerical heat transfer and fluid flow. CRC press.

Van Doormaal, J. and Raithby, G. (1984). Enhancements of the simple method for predicting incompressible fluid flows. Numerical heat transfer, 7(2):147-163.

Zeroual, M. and Cerisier, P. (2000). The effect of walls conductivity on the convective structure in a three heated walls vessel-chapter 486. Elsevier Ltd.

Zeroual, M. and Cerisier, P. (2007). Experimental study of rayleigh-bnard convection destabilized by heated sidewall. Journal of Engineering and Applied Sciences, 2(6):1048-1053. 